\title{
Tetralogy of Fallot associated with persistent common atrioventricular canal (endocardial cushion defect) ${ }^{1}$
}

\author{
Rajendra Tandon, James H. Moller, and Jesse E. Edwards \\ From the Department of Pathology, United Hospitals - Miller Division, St. Paul, Minnesota; and the \\ Departments of Pathology and Pediatrics, University of Minnesota, Minneapolis, Minnesota, U.S.A.
}

A clinicopathological analysis was made of 13 cases in which the anatomical characteristics of tetralogy of Fallot were associated either with the classical features of the complete type of persistent common atrioventricular canal ( 8 cases) or with a forme fruste of the latter ( 5 cases); that is, cleft tricuspid valve (4 cases) and isolated ostium primum (one). The ratio of female to male was Io to 3. Down's syndrome was associated in 6 of the 13 cases. Features of tetralogy of Fallot dominated the clinical picture in all cases and the diagnosis was supported by angiocardiography.

The classical form of persistent common atrioventricular canal was identifiable from both the electrocardiogram and the left ventriculogram. The electrocardiogram was characteristic - showing left axis deviation with a counterclockwise loop in the frontal plane - and when available the left ventriculogram showed the characteristic goose-neck deformity.

Only one patient with forme fruste of the atrioventricular canal showed this characteristic electrocardiographic picture. When the forme fruste was represented by a cleft in the tricuspid valve, the tricuspid regurgitation was not recognizable clinically. The right ventriculogram, however, presented evidence of tricuspid regurgitation.

Tetralogy of Fallot and persistent common atrioventricular canal each exhibit specific anatomical characteristics. While either condition may be associated with certain variations and/or other anomalies, it is uncommon to observe both conditions in the same heart. When the two are associated, each malformation has an influence in modifying the basic functional characteristics and the surgical challenges of the other. The result is an interesting entity.

Only a few cases have been reported in which tetralogy of Fallot was associated with the complete type of persistent common atrioventricular canal. For this reason, we were stimulated to describe our clinical and pathological obervations in our cases of tetralogy of Fallot associated with persistent common atrioventricular canal.

\section{Subjects and methods}

Thirteen cases with the characteristic anatomical features

Received Io August 1973.

1 This study was supported by a Public Health Service Research grant and a Research Training grant from the National Heart and Lung Institute. of tetralogy of Fallot and a form of persistent common atrioventricular canal were available for study. The cases were divided into two groups according to the type of abnormality derived from the endocardial cushion tissue. Group I consisted of 8 cases in which the persistent common atrioventricular canal was of the complete type according to the definition of Wakai and Edwards (1958). Group II consisted of 5 cases in which formes frustes of persistent common atrioventricular canal were present. In 4 of these cases (group IIa), the malformation of the atrioventricular canal was represented simply by a cleft in the septal leaflet of the tricuspid valve and, in the fifth case (group IIb), by an atrial septal defect of the atrioventricular canal type (ostium primum).

\section{Observations}

The ages of the 8 patients in group I varied from 5 weeks to 26 years. Seven were female. Five patients exhibited Down's syndrome; 4 of these 5 were female.

The ages of the 4 patients in group IIa varied from II to 26 years. Three of them were female and one of the 3 had Down's syndrome. Group IIb 


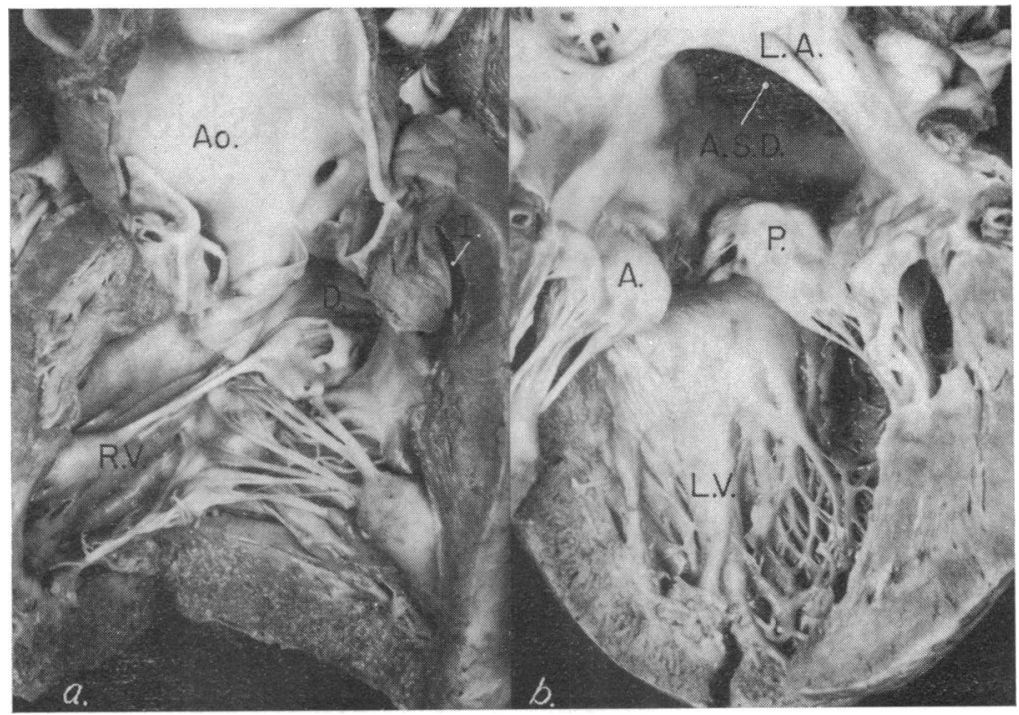

FIG. I A typical case of tetralogy of Fallot associated with the complete type of persistent common atrioventricular canal. a) View of interior of the right ventricle. The aorta (Ao.) arises above the ventricular septal defect $(D$.$) from both ventricles. The characteristic infundi-$ bular chamber (I.) of tetralogy of Fallot is portrayed. $b$ ) View of a portion of the left atrium (L.A.) and left ventricle (L.V.). Beneath the atrial septal defect (A.S.D.) that is characteristic of common atrioventricular canal is shown a cleft in the anterior leaflet of the mitral valve, yielding two components $(A$. and $P$.) which, together with elements of the tricuspid valve, had formed the anterior and posterior leaflets of the common atrioventricular valve.

consisted of a single, 2-year-old male child without Down's syndrome.

\section{Anatomical findings}

Anatomical characteristics of tetralogy of Fallot were present in each of the 13 cases (Fig. Ia). The aorta arose above the ventricular septum, thus overriding both ventricles. In each case the aorta was wider than the pulmonary trunk.

The outflow tract of the right ventricle showed various abnormalities. Valvular pulmonary stenosis was present in 9 patients, the pulmonary valve being bicuspid in 6 and dome-shaped in 3. The pulmonary valve was atretic in 2 patients and normal in the remaining 2. Infundibular narrowing was present in each patient. In Io this was in the form of infundibular stenosis, in one patient a stenosing ring was present $8 \mathrm{~mm}$ below the pulmonary valve, and in the remaining 2 patients, each of whom had pulmonary valvular atresia, the right ventricular outflow area was hypoplastic.

The special characteristics of the abnormality of the endocardial cushion follow.
Classical persistent common atrioventricular canal (group I) In the 8 patients who exhibited the complete type of persistent common atrioventricular canal, the atrial septum was deficient, with the defect lying anterior and inferior to the fossa ovalis. The superior border of the atrial defect was formed by the arched inferior margin of the septum primum. In each, the atrial defect was continuous with a deficiency in the upper portion of the ventricular septum. The defects continued through clefts in the anterior leaflet of the mitral valve and the septal leaflet of the tricuspid valve. The result was the formation of a large anterior and a smaller posterior leaflet for the common atrioventricular orifice (Fig. Ib).

Formes frustes of persistent common atrioventricular canal (group II) The atrial septum was intact in the 4 patients in group IIa, but a cleft in the septal leaflet of the tricuspid valve represented the endocardial cushion abnormality (Fig. 2). The depth of the cleft was variable, extending from halfway through the septal leaflet to the annulus. It divided the septal leaflet into an anterior and 


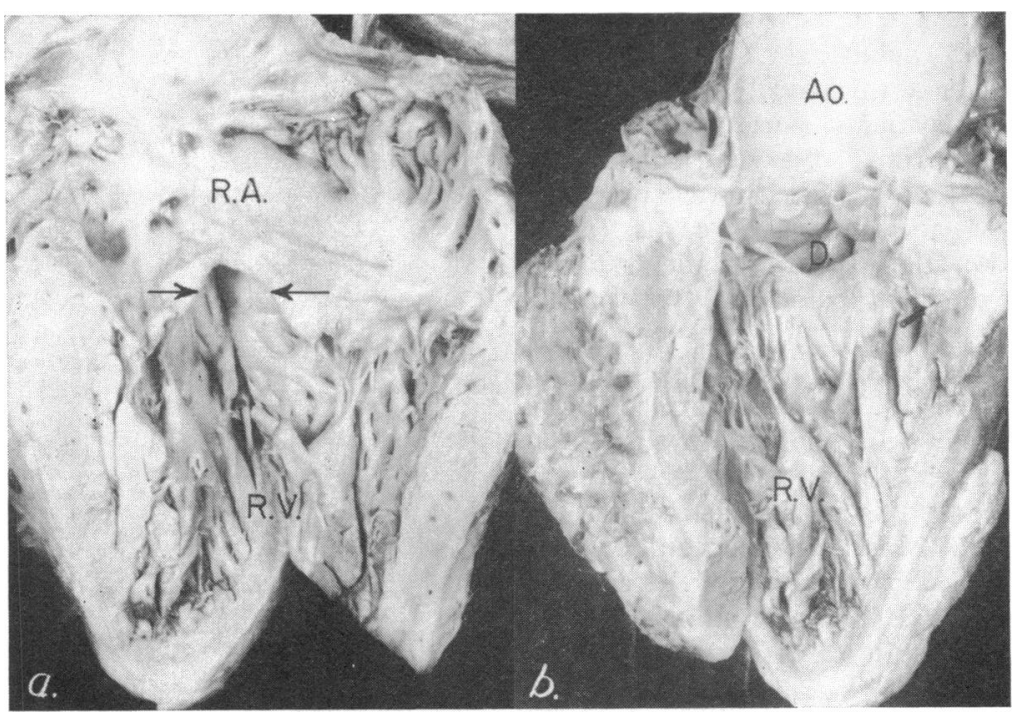

FIG. $2 A$ forme fruste of persistent common atrioventricular canal in the form of a cleft septal leaflet of the tricuspid valve associated with the tetralogy of Fallot. a) View of right atrium (R.A.) and right ventricle (R.V.). The atrial septum is intact. The septal leaflet of the tricuspid valve is cleft (between arrows). b) Right ventricle (R.V.) and aorta (Ao.). The aorta shows biventricular origin above a ventricular septal defect $(D$.$) . Probe leads to a narrow in-$ fundibulum of the right ventricle characteristic of that in tetralogy of Fallot.

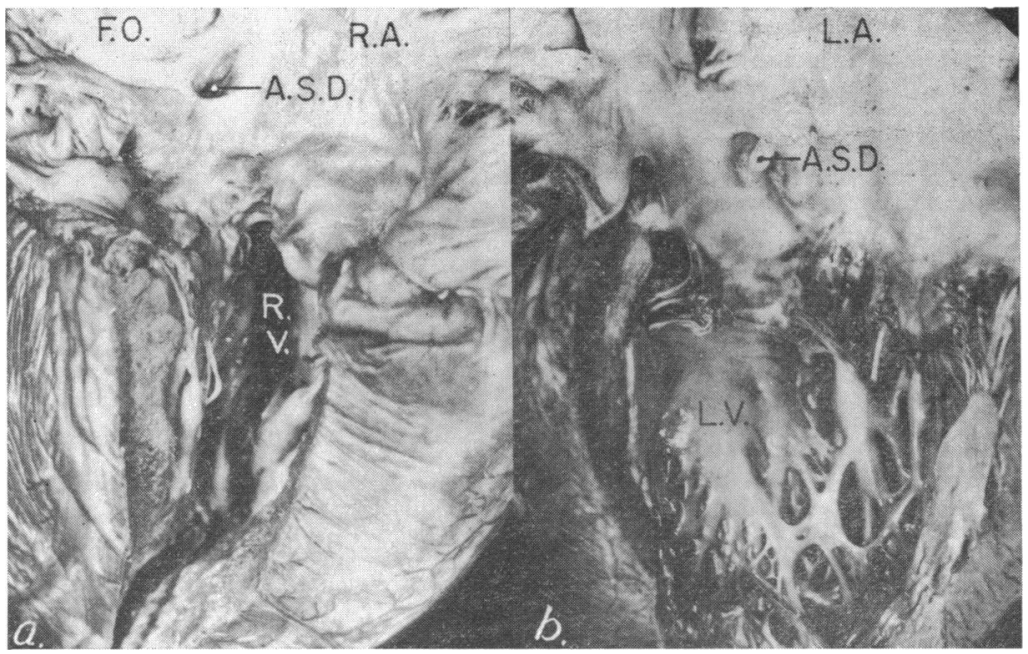

FIG. $3 A$ forme fruste of persistent common atrioventricular canal in the form of a persistent ostium primum associated with tetralogy of Fallot. a) View of right atrium (R.A.) and right ventricle (R.V.). The atrial septal defect (A.S.D.) is beneath the fossa ovalis (F.O.). b) View of left atrium (L.A.) and left ventricle (L.V.). The lower edge of the atrial septal defect (A.S.D.) is formed by the basal aspect of the anterior mitral leaflet. 
posterior segment. The posterior portion was usually smaller than the anterior. The margins of the cleft were rolled and thickened. Chordal attachments varied. In 3 patients, part of the chordae were attached to the rim of the ventricular septal defect and, in 2 of these 3, other chordae passed to the area adjacent to the aortic valve cusps. In the fourth patient, the anterior part of the tricuspid valve formed a modified parachute type of deformity.

In the one patient in group IIb, a small, $4 \mathrm{~mm}$, ostium primum type of defect was present. The defect was anteroinferior to the fossa ovalis. From the right atrial aspect, septal tissue was present between the lower border of this defect and the tricuspid ring. From the left atrial aspect, however, the defect was formed by the base of the anterior leaflet of the mitral valve (Fig. 3). Both the anterior mitral and septal tricuspid leaflets were normal.

Additional anatomical anomalies A fossa ovalis-atrial septal defect was present in 6 patients, 4 from group I and 2 from group II. The defect in the fossa ovalis merged with the atrial defect resulting from the complete type of persistent common atrioventricular canal in 2 patients of group I. The result was almost a single atrium.

Four patients in group I, and 2 in group II showed a right aortic arch with mirror image branching. A left-sided persistent ductus arteriosus was present in 2 patients, both of whom had the complete type of persistent common atrioventricular canal. In one of these patients the persistent ductus arteriosus was associated with a right aortic arch and ran between the left innominate artery and the left pulmonary artery.

When other intracardiac or related abnormalities were present, in group I, these consisted of mild cor triatriatum in I case and abnormalities of the mitral valve in 2 cases. One of these defects was a modified parachute deformity of the mitral valve; the other was attachment of the posterior leaflet of the mitral valve directly to the wall of the left ventricle. In I case severe stenosis of the left pulmonary artery was evident distal to the insertion of the ductus arteriosus. An anomalous right subclavian artery was present as the fourth branch of the aorta in one case, and a persistent left superior vena cava joined the coronary sinus in 2 cases.

\section{Clinical findings}

The predominant clinical findings in both groups of cases were those associated with tetralogy of Fallot. Cyanosis of varying degree was present in each patient, but squatting and anoxic spells were infrequent. Systolic murmurs were present in II

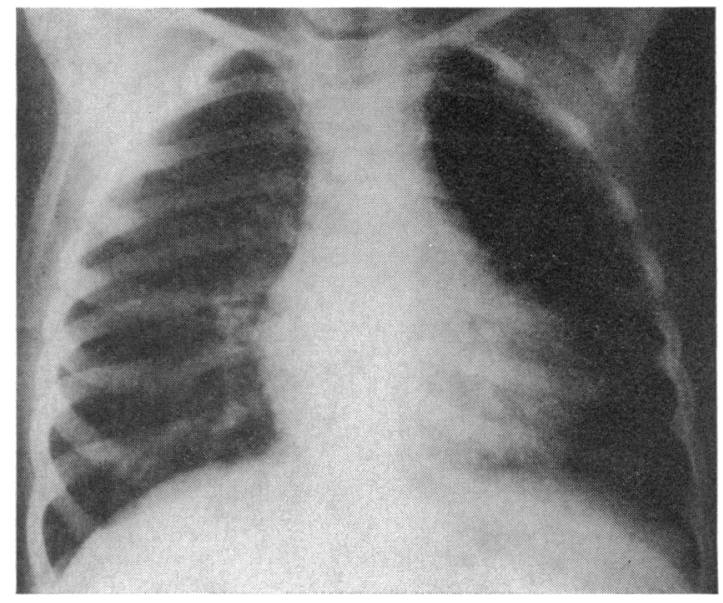

FIG. 4 Frontal $x$-ray of a 9-year-old girl with tetralogy of Fallot and the complete variety of persistent common atrioventricular canal. The picture is compatible with that of the tetralogy of Fallot.

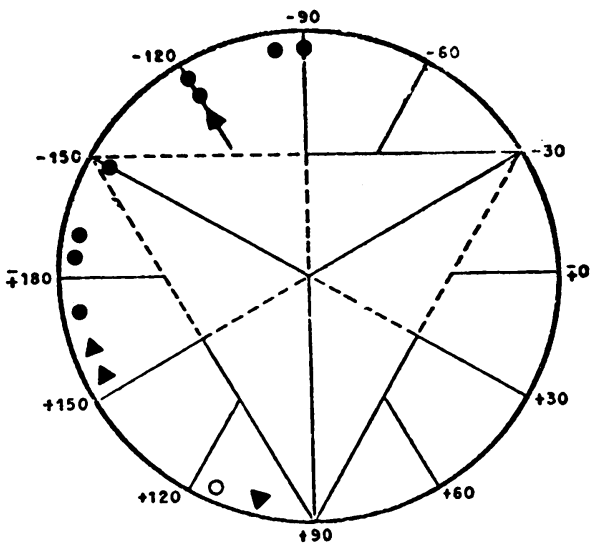

= Complete type of persistent common atrioventricular canal.

$\Delta=$ Cleft tricuspid valve.

O* Atrial septal defect of the persistent common atrioventricular canal type.

FIG. 5 Summary of the electrocardiographic axes in the 13 cases studied. With the exception of one case, all those with the complete variety of persistent common atrioventricular canal associated with tetralogy of Fallot showed left axis deviation. In the exceptional case, wherein the mean $Q R S$ axis was $+170^{\circ}$, the direction of the frontal loop was counterclockwise. Only one of the cases of forme fruste of persistent common atrioventricular canal (cleft tricuspid leaflet) showed left axis deviation and counterclockwise rotation. 
patients. These were located along the left sternal border and were either grade $3 / 6$ or grade $4 / 6$. The murmur extended to the back in group I patients. Neither of the patients with pulmonary atresia had a murmur initially but one had a continuous murmur later. The second sound was single in I I and split in 2 patients. The pulmonary component was delayed and soft in the latter 2.

\section{Radiographic findings}

The thoracic $x$-ray was believed to be classical for tetralogy of Fallot in 4 patients, 2 of whom showed a complete form of atrioventricular canal (Fig. 4). In the remaining patients, the cardiac silhouette, though characteristic for tetralogy of Fallot, showed mild to moderate cardiomegaly. The cardiac apex was upturned and the pulmonary artery segment was concave. The pulmonary vasculature was diminished in 12 patients and normal in the remaining patient.

\section{Electrocardiographic findings}

Left axis deviation was found in each of the patients with the complete form of common atrioventricular canal. The mean QRS axis in the frontal plane ranged from $-90^{\circ}$ to $+170^{\circ}$ (Fig. 5). Vectorial analysis of the QRS loop in the frontal plane revealed that the instantaneous vector advanced in a counterclockwise direction in each case (Fig. 6).

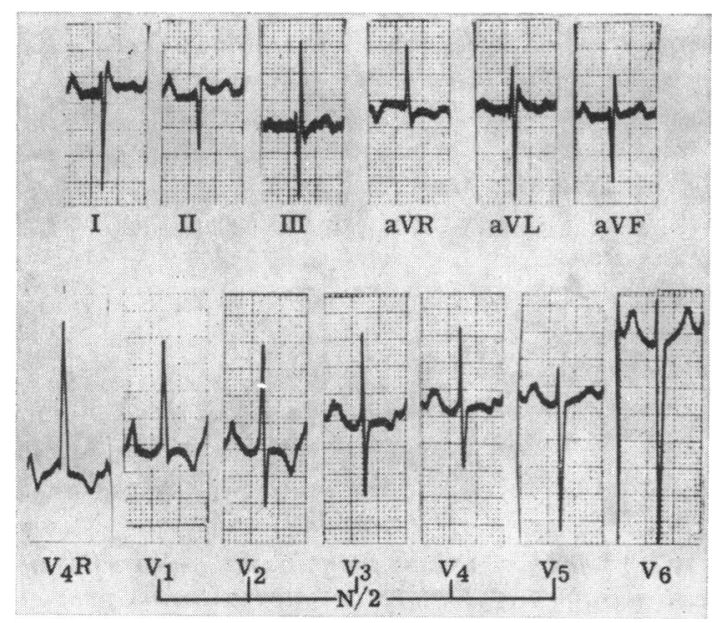

FIG. 6 Electrocardiogram showing left axis deviation with right ventricular hypertrophy in the 9-yearold girl with tetralogy of Fallot and persistent common atrioventricular canal (same case as Fig. 4). The picture is more like that of persistent common atrioventricular canal than tetralogy of Fallot.

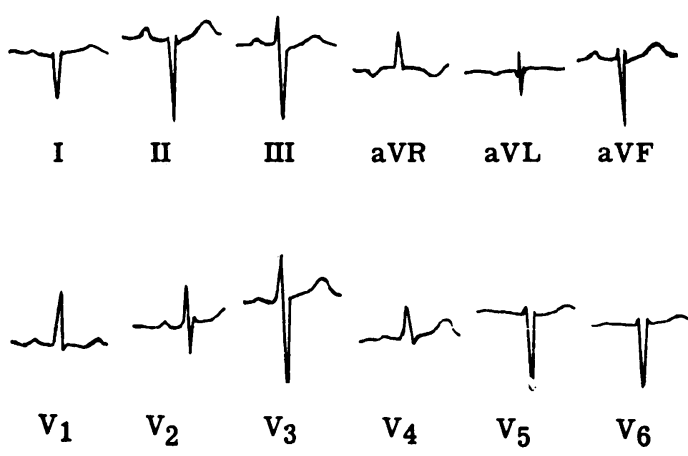

FIG. 7 Electrocardiogram from the patient whose heart is illustrated in Fig. 2 with a cleft septal leaflet of the tricuspid valve associated with tetralogy of Fallot. This is the only instance of the forme fruste of persistent common atrioventricular canal associated with the tetralogy of Fallot that shows left axis deviation.

In contrast, only I patient in group II showed left axis deviation and counterclockwise rotation of the loop (Fig. 7). The other 4 showed clockwise rotation and right axis deviation.

\section{Comment}

The pathological anatomy of tetralogy of Fallot is well known. Associated malformations have been reviewed earlier (Rao, Anderson, and Edwards 1971). The association of persistent common atrioventricular canal with tetralogy of Fallot is rare.

Twenty-four cases have been reported: Planchu and Gardère (1909), Abbott (1936), Harris and Farber (1939), Benjamin, Landt, and Zeek (1940), Warden et al. (1957), and Castleman (1957) each reported I case; McGoon, DuShane, and Kirklin (1959) described 2 cases, Fontana and Edwards (1962) described 2; Mouquin et al. (1956) reported 3; Lev, Agustsson, and Arcilla (196I) reported 3; Scott, Hauck, and Nadas (1962) described 3; and Young (1963) described 5 cases.

\section{Pathological anatomy}

The spectrum of anomalies of the atrioventricular canal associated with tetralogy varies from the complete type of persistent common atrioventricular canal to an isolated cleft in the septal leaflet of the tricuspid valve. The complete type is the commonest. Besides our 8 cases, $2 \mathrm{I}$ cases of the complete type associated with tetralogy of Fallot have been reported earlier. Transitional and partial types appear to be less common. Two cases of the tran- 
sitional variety have been reported earlier. One was seen by one of us (J.E.E.) (Fontana and Edwards, 1962), and the other by Lev et al. (196I). The description of the case reported by Warden et al. (1957) suggests the partial variety of persistent common atrioventricular canal.

The isolated cleft in the septal leaflet of the tricuspid valve, present in 4 of our cases, represents the minimal manifestation of atrioventricular canal malformations. These cases were included for 3 reasons: (I) the type of involvement of the septal leaflet of the tricuspid valve was typical of that seen in atrioventricular canal malformations; (2) Down's syndrome which is commonly associated with malformations of the atrioventricular canal was present in $I$ of these 4 cases; and (3) in I of these 4 cases the electrocardiogram (Fig. 7) was typical of that seen in malformations of the atrioventricular canal.

\section{Clinical features}

Clinically, the patients presented with symptoms and signs typical of tetralogy of Fallot. Certain features need to be emphasized, however.

Down's syndrome is frequently associated with this combination of anomalies. Of our 13 patients, 6 showed features of Down's syndrome: 5 of the 6 were from group I and I from group II. In 14 of the 24 patients with tetralogy of Fallot and persistent atrioventricular canal, whose cases have been reported elsewhere, the presence or absence of Down's syndrome is known, and 6 of these showed features of Down's syndrome. Of these 6 patients, 5 had the complete type of persistent common atrioventricular canal.

The sexes are equally represented or there is slight male predominance in tetralogy of Fallot, whereas female cases predominate when tetralogy is associated with atrioventricular canal malformations. Of our 13 patients, Io were female. Of the 20 reported cases of this association, in which sex is known, 15 were female.

Physical examination suggests tetralogy of Fallot and is mostly unrewarding in suggesting the presence of an additional atrioventricular canal malformation. The systolic murmur, however, tends to be louder and more widely radiated than in uncomplicated tetralogy of Fallot. A separate regurgitant systolic murmur of tricuspid or mitral regurgitation was not described in any of our cases. The pathological anatomy, however, suggests that it can be present and may have been responsible for the radiation of systolic murmur toward the back in the group I cases.

Slight cardiomegaly and a prominent right atrium were noted frequently in the $x$-rays in our cases of tetralogy of Fallot associated with persistent common atrioventricular canal. These radiological features, however, are not diagnostic enough to be of help in the clinical recognition of the association of atrioventricular canal malformation with Fallot's tetralogy.

The electrocardiogram is most useful in separating group I cases from cases of uncomplicated tetralogy of Fallot. In all of the group I cases, the electrocardiogram was typical of persistent common atrioventricular canal in that it showed pronounced left axis deviation. The vectorial analysis indicated that the frontal plane vector moved in a counterclockwise direction. Except in one case in which the electrocardiogram showed left axis deviation with counterclockwise direction in the frontal plane, the electrocardiogram was not helpful in separating group II cases from cases of uncomplicated tetralogy of Fallot.

The diagnosis of persistent common atrioventricular canal associated with tetralogy of Fallot can

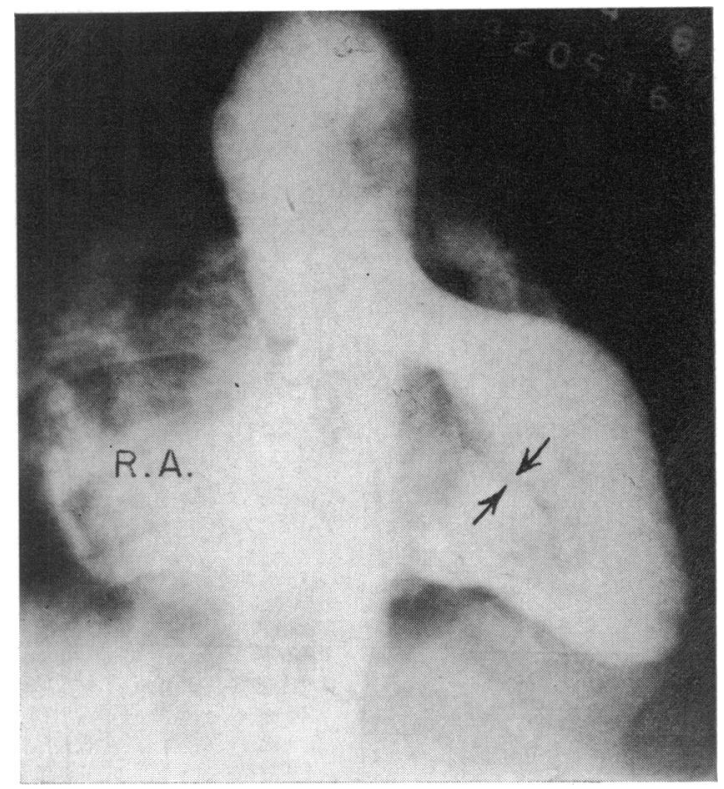

FIG. 8 Left ventriculogram in the 9-year-old girl with tetralogy of Fallot associated with the complete variety of persistent common atrioventricular canal (same case as Fig. 4 and 6). The characteristic gooseneck deformity of the latter malformation is evident. Opacification (between arrows) at base of left ventricle may be the opposing edges of the thickened tissue of the cleft mitral valve. Opacification of the right atrium (R.A.) indicates mitral regurgitation. 


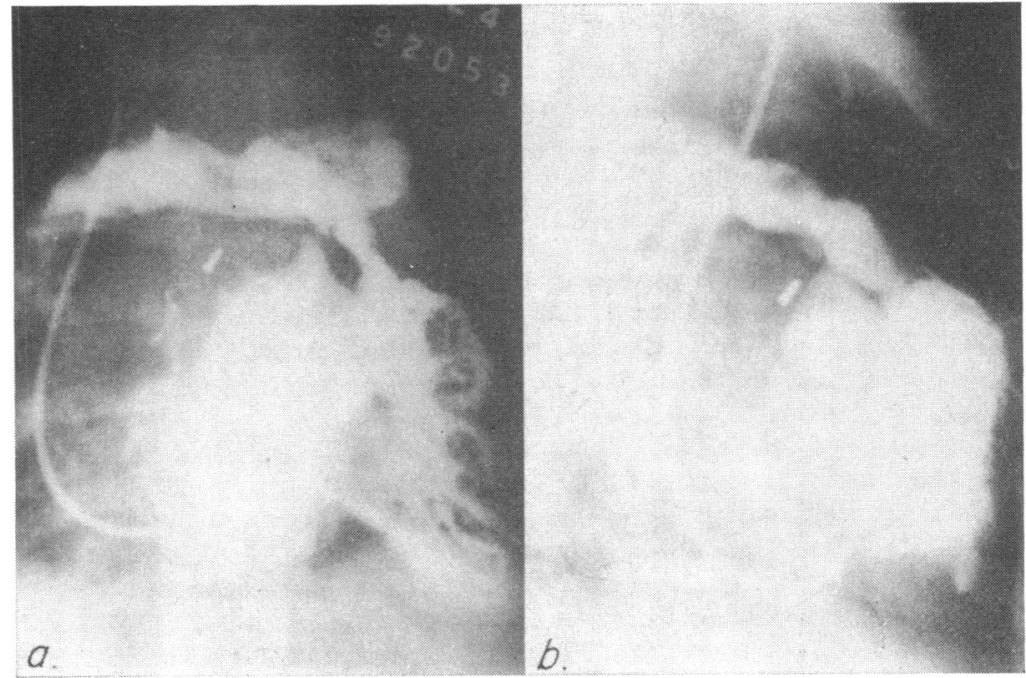

FIG. 9 Same case as Fig. 8, right ventriculograms showing the features of the tetralogy of Fallot. a) Frontal view. b) Lateral view.

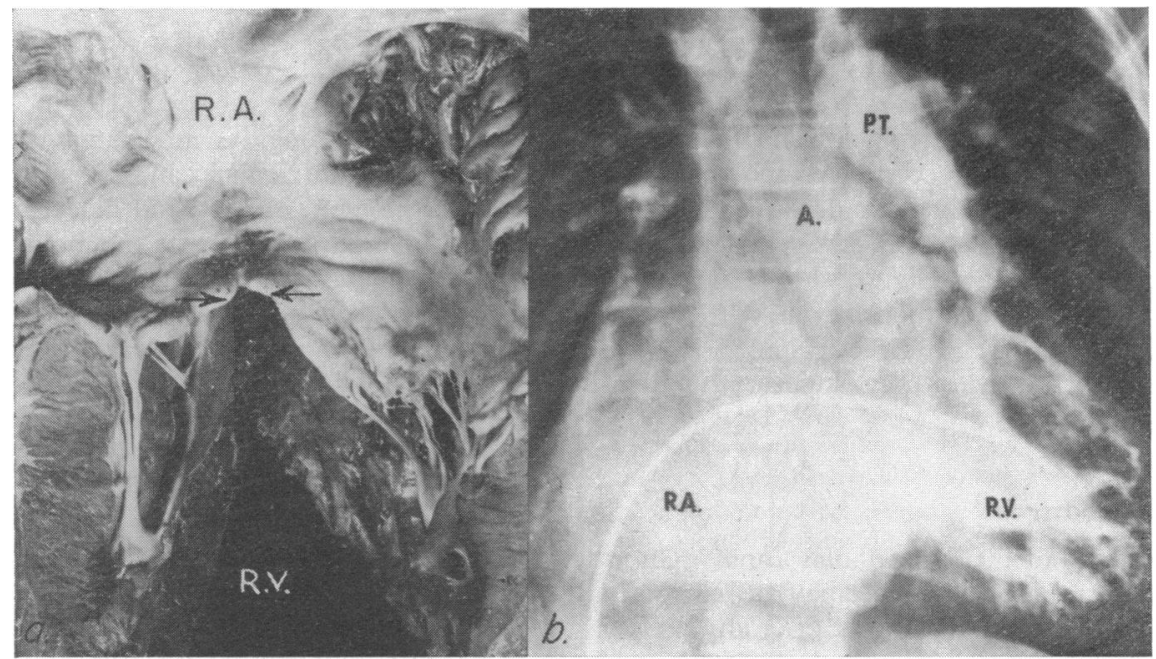

FIG. IO Cleft in a septal leaflet of the tricuspid valve associated with the tetralogy of Fallot. a) Right atrium (R.A.) and right ventricle (R.V.). The septal leaflet of the tricuspid valve shows a cleft (between arrows). $b$ ) Right ventriculogram in frontal view. In addition to showing pulmonary stenosis and opacification of the aorta $(A$.) there is opacification of the right atrium (R.A.) indicating tricuspid regurgitation and tetralogy of Fallot. 


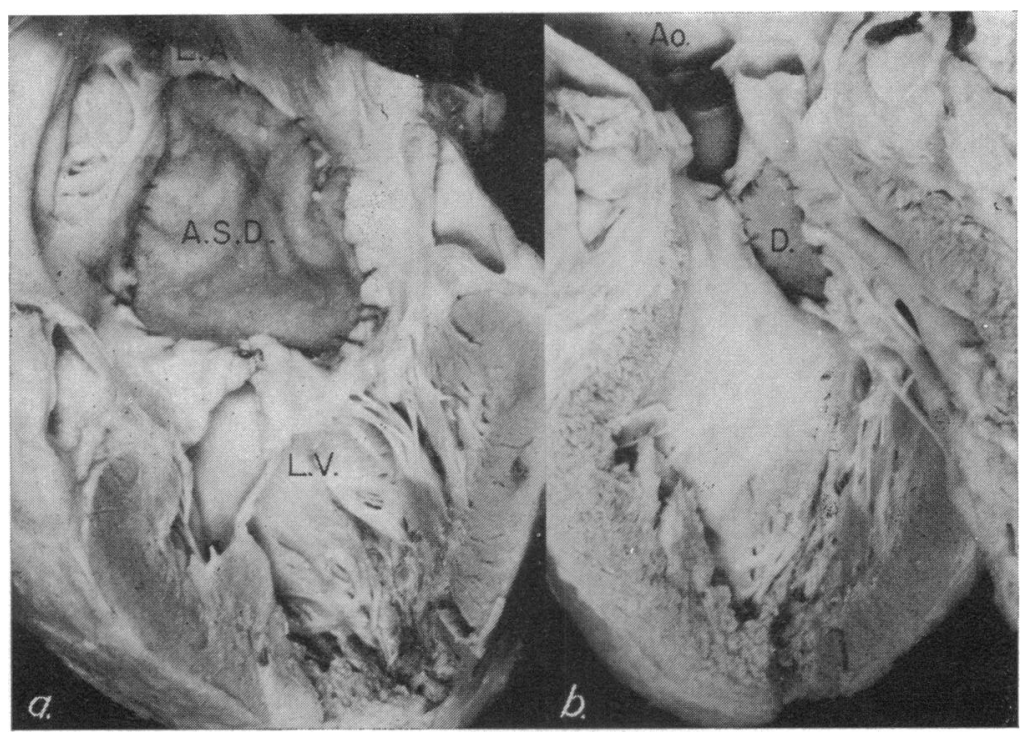

FIG. II The case of the tetralogy of Fallot in the 9-year-old girl associated with the complete variety of persistent common atrioventricular canal which had been treated surgically (same case as Fig. 4, 6, 8, and 9). a) View of left atrium (L.A.) and left ventricle (L.V.). The atrial septal defect (A.S.D.) has been closed by a 'teflon' patch. $A$ stitch has been placed across the base of the cleft in the anterior mitral leaflet. $b$ ) View of the aorta (Ao.) and left ventricle. The ventricular septal deficiency $(D$.$) has been partially closed by a patch. In spite of this, the aorta$ (Ao.) continues to arise from both ventricles because the ventricular septal defect (probe) remains open.

be suspected, but is difficult to prove at cardiac catheterization. Cineangiograms, however, were diagnostic in group I. They showed the typical goose-neck appearance secondary to the pronounced deficiency of the ventricular septum in left ventriculograms (Fig. 8). A right ventriculogram will identify the tetralogy (Fig. 9). The diagnosis in group II cases may be difficult even with angiography. Evidence of tricuspid regurgitation in right ventriculograms, however, may suggest the diagnosis (Fig. 10).

\section{Surgical procedures}

The combination of atrioventricular canal malformation with tetralogy of Fallot may be corrected surgically. Group II lesions do not offer any greater surgical difficulty than uncomplicated tetralogy of Fallot does. If the diagnosis has been established beforehand, group II lesions may be easier to correct and a right ventriculotomy may be preventable, since the cleft septal leaflet of the tricuspid valve results in a larger tricuspid valve opening and the ventricular septal defect can be more easily approached.

When the tetralogy is associated with complete common atrioventricular canal, the problem with regard to the ventricular septal defect is more complex. In the first place there is the major and characteristic deficiency of the septum peculiar to the atrioventricular malformation. In the second, the aorta exhibits the biventricular origin characteristic of tetralogy.

For surgical correction, therefore, one step is to enlarge the ventricular septum while the other is to close the communication of the right ventricle with the aorta.

We became aware of this problem when examination of a case at necropsy showed a residual ventricular septal defect, whereas the surgeon felt that it had been closed completely (Fig. II).

The differences between an uncomplicated ventricular septal defect, that of tetralogy of Fallot, and that of tetralogy of Fallot with the complete type of persistent common atrioventricular canal, are diagrammatically represented in Fig. 12. 

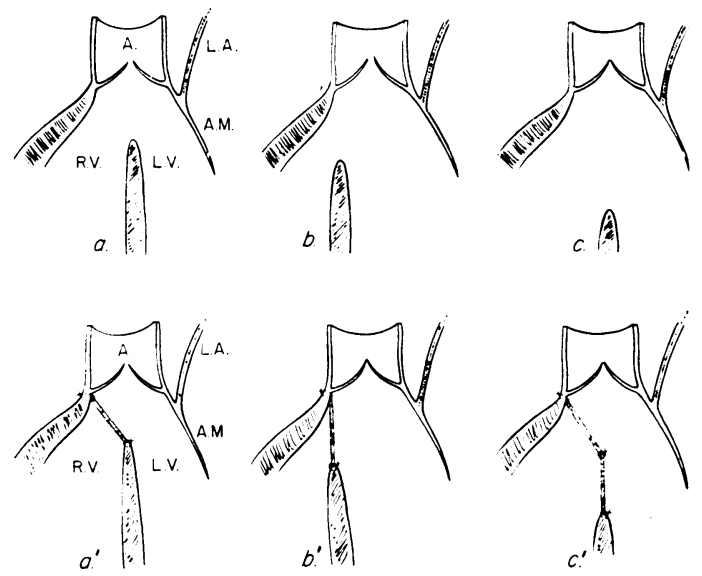

FIG. I2 Portrayal of relation of aorta to the ventricular septum in several conditions. a) The tetralogy of Fallot; the aorta arises from both ventricles above the ventricular septal defect. b) Isolated ventricular septal defect; aorta is positioned more over the left ventricle than in the tetralogy of Fallot. c) Persistent common atrioventricular canal; the aorta arises from both ventricles above a large defect which is compounded of the deficiency of the ventricular septum characteristic of persistent common atrioventricular canal and that of the tetralogy of Fallot. $a^{1}$ ) Closure of the ventricular septal defect in tetralogy of Fallot involves a diagonally placed patch which, in effect, closes communication between the right ventricle and the aorta. $b^{1}$ ) In isolated ventricular septal defect a direct closure of the ventricular septal defect may be accomplished. $c^{1}$ ) In persistent common atrioventricular canal associated with tetralogy of Fallot, the deficiency of the septum which is part of the persistent common atrioventricular canal should be repaired, but the closure of the defect which is part of the tetralogy of Fallot involves the diagonal placing of patch as in $a^{1}$ ) to obstruct the communication between the right ventricle and the aorta.

It is necessary to point out certain conduction abnormalities that are present with atrioventricular malformations and others that follow right ventriculotomy. Malformations of the atrioventricular canal are associated with left axis deviation. The exact mechanism of the left axis deviation is not known. It has been suggested that the left axis is probably due to a pronounced deficiency of the ventricular septum resulting in abnormality in the direction of depolarization (Goor, Lillehei, and Edwards, 1968). It could be due, however, to a block of the anterior division of the left bundle
(Liebman and Nadas, 197I). Vertical ventriculotomy has been shown to result in complete right bundle-branch block in 100 per cent of cases (Gelband et al., 1971). The right bundle-branch block following vertical ventriculotomy is probably a block at a more peripheral level since the right bundle is not near the ventriculotomy. Such a block, therefore, may not have the same significance as a block occurring at a proximal level (Gelband et al., I97I). The presence of left axis deviation with right bundle-branch block, nevertheless, suggests that 2 of the 3 fasciculi may be blocked. This leaves only the posterior division of the left bundle intact for conduction of sinus beats to the ventricle. Findings of Moss, Klyman, and Emmanouilides (1972) suggest that some patients with left axis deviation and right bundle-branch block later develop complete heart block. The conduction abnormalities, therefore, should be viewed with concern, and the patients followed closely for indefinite periods after operation.

\section{References}

Abbott, M. E. (1936). Atlas of Congenital Cardiac Disease. American Heart Association, New York.

Benjamin, J. E., Landt, H., and Zeek, P. (1940). Persistent ostium atrioventricular commune in a heart which functioned as a biloculate organ; report of a case including autopsy in an eighteen-year-old girl. American Heart Fournal, 19, 606.

Castleman, B. Ed. (1957). Case records of the Massachusetts General Hospital; Case 4340r. New England fournal of Medicine, 257, 672 .

Fontana, R. S., and Edwards, J. E. (1962). Congenital Cardiac Disease; a Review of 357 Cases Studied Pathologically. Saunders, Philadelphia.

Gelband, H., Waldo, A. L., Kaiser, G. A., Bowman, F. O., Jr., Malm, J. R., and Hoffman, B. F. (I97I). Etiology of right bundle-branch block in patients undergoing total correction of tetralogy of Fallot. Circulation, 44, 1022.

Goor, D., Lillehei, C. W., and Edwards, J. E. (1968). Further observations on the pathology of the atrioventricular canal malformation. Archives of Surgery, 97, 954.

Harris, J. S., and Farber, S. (1939). Transposition of the great cardiac vessels; with special reference to the phylogenetic theory of Spitzer. Archives of Pathology, 28, 427.

Lev, M., Agustsson, M. H., and Arcilla, R. (I96I). The pathologic anatomy of common atrioventricular orifice associated with tetralogy of Fallot. American fournal of Clinical Pathology, 36, 408.

Liebman, J., and Nadas, A. S. (1971). An abnormally superior vector (formerly called marked left axis deviation). American fournal of Cardiology, 27, 577.

McGoon, D. C., DuShane, J. W., and Kirklin, J. W. (1959). The surgical treatment of endocardial cushion defects Surgery, 46, 185 .

Moss, A. J., Klyman, G., and Emmanouilides, G. C. (1972). Late onset complete heart block; newly recognized sequela of cardiac surgery. American fournal of Cardiology, 30, 884 . 
Mouquin, M., Metianu, C., Durand, M., and Beyda, E. (1956). Cardiopathie congénitale complexe; syndrome associant aux éléments de la tétralogie de Fallot, un orifice auriculo-ventriculaire commun et une communication inter-auriculaire large; rapport de 3 cas anatomiques personnels. Cardiologia, 29, 145.

Planchu, and Gardère (1909). Un cas de cyanose congénitale avec malformations cardiaques multiples; chez un nourrisson mort par endocardite infectieuse. Archives de Médicine des Enfants, 12, 201.

Rao, B. N. S., Anderson, R. C., and Edwards, J. E. (197I). Anatomic variations in the tetralogy of Fallot. American Heart fournal, 81, 36r.

Scott, L. P., Hauck, A. J., and Nadas, A. S. (1962). Endocardial cushion defect with pulmonic stenosis. Circulation, 25, 653 .

Wakai, C. S., and Edwards, J. E. (1958). Pathologic study of persistent common atrioventricular canal. American Heart fournal, 56, 779.

Warden, H. E., DeWall, R. A., Cohen, M., Varco, R. L., and Lillehei, C. W. (1957). A surgical-pathologic classification for isolated ventricular septal defects and for those in Fallot's tetralogy based on obervations made on 120 patients during repair under direct vision. Fournal of Thoracic Surgery, 33, 21.

Young, D. (1963). Criteria for surgery in persistent common atrioventricular canal. American fournal of Cardiology, 12, 80.

\section{Addendum}

Since completion of this manuscript, we have observed an additional case in which tetralogy of Fallot was asso- ciated with certain features of the persistent common atrioventricular malformation. This case is summarized below.

The clinical diagnosis in this 8-year-old boy was tetralogy of Fallot. There were no features of Down's syndrome. The electrocardiogram showed a mean frontal plane $Q R S$ axis of a $+170^{\circ}$, with a clockwise frontal plane loop and right ventricular hypertrophy. The thoracic radiograph was typical for the tetralogy. The patient died three days after complete correction of tetralogy of Fallot.

At necropsy, the heart showed classical features of tetralogy of Fallot in addition to certain features of persistent common atrioventricular canal. The latter took the following forms. While the atrial septum was intact, there were discontinuous clefts within the anterior mitral and septal tricuspid leaflets. The latter two valves were continuous through the ventricular septal defect. The anterior mitral leaflet was attached to the ventricular septum by short chordae resulting in subaortic stenosis.

\section{Comments}

The findings of this case further illustrate that a wide spectrum of atrioventricular canal defects may be associated with tetralogy of Fallot.

Requests for reprints to Dr. J. E. Edwards, Department of Pathology, United Hospitals-Miller Division, 125 West College, St. Paul, Minnesota 55102, U.S.A. 